\title{
Arts and Crafts -liikkeen muotoilijat vålittåjinå
}

Juha Ågren

Artikkelini päämääränä on esitellä 1800-luvulla Englannissa toimineiden Arts and Crafts Movementin muotoilijoiden tekstejä, joiden tarkoitus oli vaikuttaa heidän omien tuotteidensa myynnin edistämiseen. Aiemmasta Arts and Crafts Movementin tutkimuksesta aiheesta on kirjoitettu mm. Charles Harveyn ja Jon Pressin toimittamassa teoksessa William Morris; Design and Enterprise in Victorian Britain. Teos käsittelee William Morrisin muotoilun idealismin pohjalta syntynyttä liiketoimintaa. Oma tutkimukseni nostaa esiin brittiläisten 1800-luvun lopun muotoilijoiden taidealan julkaisuja foorumina käyttäneen keskustelun käytännön työstä muotoilutuotemarkkinoilla. Tekstini keskittyy 1800-luvun brittiläisen taidelehdissä käydyn keskustelun kysymyksiin, jotka ohjasivat käyttöesineiden muotoilua.

\section{Muotoilutaiteen edellytykset 1800-lu- vun viimeisen neljänneksen aikana}

Isossa-Britanniassa 1800-luvun jälkipuoliskolla sisustustuotteiden kysyntä kasvoi talouskasvun myötä. Teollisen tuotannon osuus Ison-Britannian kansantuotteesta muihin talouden osa-alueisiin verrattuna pysyi suurin piirtein muuttumattomana 1800-luvun aikana. Nopeasti teollistuneen yhteiskunnan elinkeinorakenteen muutos näkyi kuitenkin erityisesti siten, että vuosina 1830-1914 maataloudessa työskentelevien määrä romahti ja kaupungeissa palvelualoilla työskentelevien määrä kasvoi vastaavalla tavalla. Samalla Ison Britannian kansantuote kohosi 3,3 kertaiseksi. ${ }^{1}$

Isossa-Britanniassa palkat nousivat 1800-luvun kolmannen neljänneksen ajan samalla kun uudet teolliset valmistusteknologiat laskivat tuotteiden hintoja. Vuosien 1874 ja 1896 välillä kuluttajahinnat putosivat noin $40 \%$. Nämä tekijät toivat sisustustuotteet keski- ja työväenluokkien ulottuville. Uusia taloja rakennettin alle 50000 ainoastaan kolmena vuotena vuosien 1856 ja 1908 välillä. Siten talojen rakennus ja sisustus tulivat merkittäviksi talouden alueiksi. Rakentamiseen panostaminen pysyi tahdissa väestön kasvun kanssa ja seurauksena asuntojen laatu parani. Talojen keskimääräinen koko kasvoi, ne olivat paremmin sisustettuja ja niissä oli enemmän ylellisyystuotteita. ${ }^{2}$

\section{William Morris esteetikkona, teolli- suusmiehenä ja taideteollisuuden uu- distajana}

William Morrisin (1834-1896) työ toimii hyvänä lähtökohtana estetismin ideoiden tutkimiseen kaupallisena toimintana, koska hän 
oli menestyvä teollisuusmies sen lisäksi että hänet tunnettiin Arts and Crafts Movementin johtohahmona. Morris, Marshall, Faulkner \& Co yrityksen perustaminen vuonna 1861 oli estetistisen sisustustaiteen alkusysäys 1800-luvun loppupuoliskon huonekalutuotannossa. Kaupallisen muotoiluyrityksen osakkaat olivat Ford Madox Brown, Edward Burne-Jones, Charles Faulkner, Peter Paul Marshall, William Morris, Dante Gabriel Rossetti ja Philip Webb.

William Morris aloitti yrityksensä 1860-luvun uusgotiikan kirkonrakennusprojektien alihankkijana. Uusgotiikan tyylin mukaisten uusien kirkkojen rakennuksen aikakausi oli huipussaan ja sen vaikutuksena muotoilijoiden ja koristetaitelijoiden kysyntä oli vahvaa. Kirkkojen lasimaalaukset olivat Morris \& Co:n liiketoiminnan kasvun lähtökohta. South Kensingtonin kansainvälinen näyttely vuonna 1862 oli merkkipaalu yrityksen kaupalliselle menestykselle, sillä yrityksen tuotteet voittivat siellä kaksi kultamitalia. Alkumenestyksestä huolimatta lasimaalaukset olivat epävarma pohja yritykselle ja niiden myynti romahti jyrkästi 1865-1866 huippuvuosien jälkeen. Kirkonrakennuksen vähenemisen seurauksena Morris alkoi tehdä eroa uusgotiikkaan 1870- ja 1880-lukujen kirjoituksissaan.

Essessään The Art of the People (1879) William Morris esittää ohjelmanjulistuksensa, jota on myöhemmin pidetty Arts and Crafts Movementin mottona: "Taidetta joka on inmisen inmistä varten tekemää, tuottaen iloa sekä tekijälle että käyttäjälle”. ${ }^{3}$

Asuntorakennustoiminnan kiihtymisen vuoksi ei ole yllättävää että William Morris alkoi kirjoittaa taideteollisuuden kehittämisestä samaan aikaan 1870-luvulla kun uusgotiikan kirkonrakennusprojektit saatiin valmiiksi. Kasvavasta keskiluokasta tuli uusi yleisö koristetaiteen tuotteille yleisten reaalitulojen noustessa ja Morrisin tekstit käsittelivät muotoilun sosiaalista merkitystä. Kehitys johti korkeatasoisten huonekalujen kysynnän nousuun, johon Arts and Crafts Movementin menestys 1880- ja 1890-Iukujen osin perustui.

The Arts and Crafts Exhibition Societyn ensimmäinen näyttely Lontoossa vuonna 1888 toimi esikuvana taideteollisuuden tuotteille omistetuille näyttelyille Englannissa. Malli näyttelylle oli otettu paremminkin kuvataidenäyttelyistä kuin kauppa- ja teollisuusmessuista, joissa taideteollisuuden tuottei- ta oli esitelty siihen saakka. Näyttelyt olivat merkittävä osa markkinointiprosessia, koska ne esittelivät uudistuneen muotoilun käsinkosketeltavasti yleisölle.

1800-luvun viimeisen neljänneksen aikana Isossa-Britanniassa massamedia laajeni lukuisten aikakaus- ja sanomalehtien julkaisemisen myötä. Kun Morris \& Co perustettiin vuonna 1861, Isossa-Britanniassa oli kaksitoista taiteeseen erikoistunutta aikakauslehteä. William Morrisin aloittaessa muotoilun uudistamiseen pyrkivän julkaisutoiminnan vuonna 1877 julkaisuja oli 22, ja kun Arts and Crafts Exhibition Society aloitti toimintansa 1888, julkaisujen määrä oli 48. Vuoteen 1899 mennessä julkaisujen määrä oli 65. Määrä oli siis kolminkertaistunut 1800 -luvun viimeisen neljänneksen aikana. ${ }^{4}$

\section{Taide, teollisuus ja koristeluntarve}

The Arts and Crafts Exhibition Societyn jäsenyys yhdisti käsittelemäni taidealan julkaisujen keskusteluun osallistuneet muotoilijat. ${ }^{5}$ Puhun tässä yhteydessä muotoilijoista, suunnittelijoista ja käsityöläisistä, jotka työskentelivät kaupallisuuden ja muodin paineiden alaisina, mutta keskittyivät esteettisyyden merki- 
tykseen taideteollisuustuotteissa ja tuotannossa.

Muodista keskusteleminen tuli tärkeäksi, kun kirjoittajat lähestyivät muotoilun käytäntöä ja halusivat erottua teoreettisesta ja periaatteellisesta kirjoittamisesta. Kyseisten muotoilijoiden kaupallisten toimien tarkastelussa on syytä ottaa huomioon William Morrisin ja muiden 1800-Iuvun loppupuoliskon muotoilijoiden pyrkimys saavuttaa sosiaalinen muutos ja elämänlaadun kehitys esittelemällä paremmin suunniteltuja sisustustuotteita. Nämä muotoilijat eivät toimineet ylellisyystavaramarkkinoilla, vaan he tekivät käyttötavaroita.

Muotoilija ja Arts and Crafts Exhibition Societyn perustajajäsen Lewis F. Day oli yksi ahkerimmista uutta muotoilua peräänkuuluttaneista kirjoittajista. Hän pyrki erottumaan aiemmista yrityksistä tehdä säännöt uusgotiikan muotoilulle. Art Journalin kirjoituksessaan "The Lowly Arts" vuonna 1882 hän halusi tehdä eron Owen Jonesin (1809-1874) ohjekirjamaisen 1856 julkaistun The Grammar of Ornamentin kaltaisiin teoksiin, jotka olivat merkittäviä brittiläiselle uusgotiikalle: “... me voisimme verrata koristetaidetta kieleen, joka elää ja kehittyy samalla tavalla...", Day kir- joitti, "Taivas varjelkoon että meidän pitäisi aina puhua kieliopin mukaan". ${ }^{6}$

Koristeluntarve, decorative want, oli Lewis F. Dayn Art Journalissa vuonna 1882 esittelemä käsite. Dayn "The Lowly Arts" artikkelin mukaan muotoilija on "omasta voimastaan tietoinen nero"7. Koristeluntarve liittyi täten luovaan toimintaan vaikuttaviin ulkopuolisiin vaatimuksiin. Koska Dayn mukaan koristeluntarve esiintyy inmisissä luonnostaan, muotoilijan rooli oli toimia välittäjänä vapaan luovan taiteilijan sijaan. Kuitenkaan välittäjänä toimiminen ei sulkenut pois taiteilijan ilmaisua. Muotoilijan tuli kuitenkin Dayn mukaan vastata muista taiteilijoista eroavalla tavalla ulkoisiin vaatimukseen, ja hänen näkemyksensä mukaan oli olemassa jopa tietty näkymätön voima joka ajoi heitä sopeutumaan näihin vaatimuksiin. Tämä voi selvittää paremmin miten Arts and Craftsin muotoilijat näkivät itsensä taiteilijoina. ${ }^{8}$

1800-luvun lopulla brittiläiset taiteilijat pohtivat myös kysymystä siitä, onko käyttöesineitä mahdollista nähdä itsenäisinä taideteoksina eri tavoin kuin esimerkiksi arkkitehtuuri- tai kuvataideteoksia. Day epäili taiteen hyötyyn yhdistämistä ja pohti käsityön arvon alenemista koristetaiteessa tekstissään "Meaning in Ornament", joka julkaistiin The Art Journalissa vuonna 1887. Day totesi, että "mitä yksilöllisempi luonne tuotteella on, sitä hankalammin se sopii sarjatuotantoon". ${ }^{9}$

Muotoilija, kuvataiteilija ja kuvittaja Walter Crane, joka oli myös Arts and Crafts Exhibition Societyn perustajajäsen ja puheenjohtaja vuosina 1888-1893 ja 1896-1912, osallistui keskusteluun Magazine of Artin 1893 kirjoituksella ja The Bases of Design -kirjassaan vuonna 1898. Hänen mielipiteensä mukaan koristetaiteilijoiden työskennellessä käyttötavaroiden parissa ja vastaamassa ulkoisiin vaatimuksiin, saattoi taiteilijalla silti olla yksilöllisiä näkemyksiä, mutta heidän työnsä täytyi nähdä suhteessa ympäröiviin olosuhteisiin. Cranen mukaan esineen luonnonmukaisuus määräytyi henkilökohtaisten mieltymysten lisäksi kolmen näkökohdan mukaan: koristeltava esine, esineen materiaali ja olosuhteet joissa esine nähdään. Koristetaiteen perustana olivat Cranella arkkitehtoniset näkökohdat, jotka määrittelivät koristelun luonteen, mittakaavan ja koristelun osien suhteet. Esineen käyttö määräsi lopullisen muodon ja toiminnot. ${ }^{10}$ 
Luennossaan Architectural Associationille vuonna 1898 Henry Wilson, muotoilija ja Arts and Crafts Exhibition Societyn jäsen, väitti arkkitehtuurin olevan sosiaalinen taide, joka ei pysty ilmaisemaan yksilöllisyyttä kuten kuvataide ja käsityö. Taidemuotojen merkityksen vertaaminen sen sijaan että ne nähtiin tukemassa toisiaan, voitiin tässä yhteydessä nähdä yrityksenä nostaa koristetaiteen arvoa omana taidemuotonaan. ${ }^{11}$ Wilsonin näkemyksen mukaan koristetaide oli enemmän yhteydessä arkkitehtuuriin kuin kuvataiteeseen, koska molemmat olivat materiaalin ja käyttötarkoituksen sanelemia.

\section{Taide ja koneellistuminen}

Artesaanin käytöllä muotoilijoiden ammattinimikkeenä oli tarkoitus nostaa käsityötaidon arvostusta sosiaalisessa asteikossa 1800 -luvulla. ${ }^{12}$ Teollisten valmistusmenetelmien yhteydessä 1800-luvun lopun brittiläiset kirjoittajat taas puhuivat mielellään edistyksestä ja kehityksestä.

Charles Eastlake (1836 - 1906) oli alustanut koneellisen ja käsityötaidon yhteenliittämisen jo vuonna 1868 teoksessaan Hints of Household Taste julistaessaan koneiden olevan sopivia niiden esineiden osien valmista- miseen joissa ei ollut koristelua. ${ }^{13}$ Muut kirjoittajat vetosivat William Morrisin ajatuksiin puolustaessaan koneiden käyttöä muotoilun tuotannossa. Muotolija ja Arts and Crafts Exhibition Societyn jäsen G.T. Robinson kirjoitti The Art Journalissa vuonna 1883 koneiden käytöstä Morrisin tuotannossa: "Hän hyväksyy rohkeasti mekaanisen sarjatuotannon välittömän tarpeen." ${ }^{14}$

Lewis F. Dayn The Art Journalissa vuonna 1885 julkaistussa tekstissä William Morrisin opit työläisen onnesta muokattiin uuteen muotoon. Morrisin ajatus siitä, että käsityömenetelmät sinällään tuottavat iloa työntekijälle, on Dayn artikkelissa käännetty koneellisuuden etujen korostamiseen, koska koneet säästävät työntekijää hankalimmilta tuotantovaiheilta. ${ }^{15}$ Magazine of Artissa vuonna 1886 Day tahtoi kuitenkin jo nähdä taiteen ammatimaisen tuotannon vastakohtana. ${ }^{16}$

1890-Iuvun kirjoituksissa tärkeäksi keskustelun aiheeksi nousi tietoisuus muotoilun kustannuksista. Walter Crane kirjoitti teoksessaan The Claims of Decorative Art vuonna 1892: "Taiteellinen työ laahaa tieteellisten keksintöjen perässä... kaupallisuuden kiireisyys painostaa suunnittelijaa". The Art Journalissa vuonna 1893 Lewis F. Day kä- sitteli muotoilijan kyvyttömyyttä tuottaa yksilöllisiä esineitä, koska monien tahojen edut sisältyvät muotoiluun. ${ }^{17}$

Muotoilijan ja Arts and Crafts Exhibition Societyn jäsenen Arthur Silverin The Studio -julkaisuun vuonna 1894 tehdyssä haastattelussa, hän totesi että valmistajat eivät uskalla sijoittaa pelkästään mielikuvituksella ja yksilöllisyydellä varustettuun muotoilijaan. Siten niin kutsutusta käytännöllisestä estetiikasta, practical aesthetism, tuli tärkeää taiteilijan menestykselle. ${ }^{18}$ Frederick Wedmore taas haastatteli Walter Cranea The Studiossa vuonna 1894 . Wedmore kysyi suoraan taiteilijan riippumattomuudesta ja Crane totesi valmistajien antavan hänelle "melko paljon vapautta valita koristetaiteen materiaalit". ${ }^{19}$

Puhdasta muotoilua ja käsityötä käsitelleissä kirjoituksissa materiaalien hinnat olivat myös tärkeä kysymys. Arts and Crafts Exhibition Societyn jäsen Reginald Blomfield antoi suoraviivaisen ohjeen huonekalujen valitsemiseen The Magazine of Artin sivuilla vuonna 1896: "Huonekalujen määrän voi lähes puolittaa, jolloin käsityön laatuun voi sijoittaa enemmän."20 Vuoteen 1900 mennessä Day oli omaksunut kannan jonka mukaan William Morrisin tuotteet tuskin oli tarkoitet- 
tu massojen kulutettaviksi, koska Morris ei luottanut koneisiin ottaakseen niistä hyödyn. Tämä johti Dayn mukaan siihen, että vain harvoilla oli varaa maksaa käsityön määräämä hinta Morrisin tuotteista. ${ }^{21}$

\section{Järjestäytynyt markkinointi}

Molemmat 1800-luvun käsitteet, koristeluntarve ja käytännöllinen estetiikka, ovat osoituksia siitä, miten käsitellyt muotoilijat eivät keskustelleet samankaltaisista oikean suunnittelun periaatteista kuin uusgotiikan koristetaiteilijat. Koristeluntarve ja käytännöllinen estetiikka voidaan nähdä kiertoilmauksina muodin seuraamiselle, joka seurasi brittiläisten muotoilijoiden asiakaskunnan muutoksesta. Valtio ja julkiset toimeksiantajat korvautuivat kaupallisilla markkinoilla kilpailevilla muotoilualan yrityksillä. Taiteellisia arvoja omaavien huonekalujen valmistajat ymmärsivät tuotteidensa olevan varsin hintavia ja heidän piti vakuutella kuluttajia omaksumaan ajatus, miksi heidän tulisi valita heidän edustamaansa suunnittelua halvemman tuotannon sijaan.

Arts and Crafts Exhibition Societyn arkistossa olevien jäsenluetteloiden perusteella yhdistys hallitsi uuden taideteollisuuden jul- kisuuskanavia 1800-luvun viimeisellä neljänneksellä Englannissa. Yhdistyksen jäseninä olivat tärkeimmät aikakauden taidetta ja muotoilua käsitelleissä julkaisuissa esitelleet kirjoittajat ja lisäksi jäsenet valitsivat taideteollisuus- ja käsityönäyttelyiden näytteilleasettajat jäsenten toimiessa myös muotoilukilpailujen tuomareina. Yhdistyksen komitean jäseniin kuuluivat kaikki puhdasta, täysin kaupallisesta eroavaksi tarkoitettua muotoilua edistäneiden yritysten johtajat. The Arts and Crafts Exhibition Societyn näyttelyjä käsitelleet tekstit olivat saman yhdistyksen jäsenten kirjoittamia, ja näissä artkkeleissa jopa listattiin hyviä muotoilijoita, jotka luonnollisesti olivat The Arts and Crafts Exhibition Societyn jäseniä.

Näistä syistä olisi oikeutettua puhua Arts and Crafts Movementin yhteydessä suoranaisesta Arts and Crafts Exhibition Societyn julkisuusdiktatuurista, joka määritteli hyväksyttävän muotoilun. Arts and Crafts Exhibition Societyn ulkopuolelta ei olisi päässyt esiin Englannin merkittävimmissä näyttelyissä tai taideteollisuutta käsittelevissä julkaisuissa. Aiemmin tässä artikkelissa käsitellyissä teksteissä uuden puhtaan muotoilun oli tarkoitus olla vapaampaa kuin uusgotiikan oikean ja väärän sääntöihin perustuva muotoilu. Hierarkia, jossa muotoilijaa ohjanneet ulkoiset tekijät määräsivät tuotteen muodon, oli kuitenkin väistämätön seuraus ihanteiden noudattamisesta, kun tuotteet oli tarkoitettu kaupalliseen jakeluun.

Pitääkseen välimatkaa kaupallistumiseen, 1800-Iuvun loppupuolen brittiläiset muotoilun uudistajat näkivät omien tuotteidensa edustavan muita puhtaampia arvoja, kuten moraalista tai luonnollista, jotka yhdistyivät edistyksen ja kehityksen inanteisiin. Mutta 1800-luvun loppuun mennessä Arts and Crafts Exhibition Societyn piirin muotoilijat ja taiteilijat myönsivät vastaavansa kaupallisten tilaajien vaatimuksiin. Taidelehdissä käyty keskustelu osoittaa miten heidän muotoilunsa haki omaa paikkansa sisustustuotemarkkinoilla. Julkaistessaan tekstejään laajemmalle yleisölle Arts and Crafts Exhibition Societyn toiminnan voi nähdä markkinointina, jonka tarkoitus oli antaa oikeutus teollisuuden rajoituksista vapaamman puhtaan muotoilun hinnalle.

\section{Viitteet}

1 Roderick Floud, The People and the British

Economy (Oxford University Press, 1997), 6, 27-28, $59-60$. 
2 Ibid., 27-28, 59-60.

3 William Morris, "The Art of the People", The Collected Works of William Morris, Volume XXII (New York: Russell \& Russell, 1879), 309.

4 Helene E. Roberts, Helene E., "British Art

Periodicals of the Eighteenth and Nineteenth

Centuries", The Victorian Periodicals Newsletter,

Number 9, July 1970: 136-168.

5 Jäsenluettelot: Archive of Arts and Crafts

Exhibition Society.

6 Lewis F. Day, "The Lowly Arts". The Art Journal 1882: 343.

7 Ibid., 342

8 Lewis F. Day: "It is admitted to be characteristic of genius that it is conscious of its own power. The men who have done great things are those who felt that it was in them to do something, and in spite of discouragement, did it. The art of ornamentist grows naturally out of some circumstance with which he has nothing to do...very often it grows out of use.

Successful decoration begins from the feeling of the decorative want." Ibid., 342-343.

9 Lewis F. Day, "Meaning in Ornament", The Art Journal 1887: 238-239.

10 Crane tiivistää ajatuksiaan koristetaiteesta kirjassaan Walter Crane, The Bases of Design London: George Bell and Sons, 1898. Ks. myös"[-] architectural considerations lie at the basis of design and control its general character, its scale and relationships; and that utility determines and specializes its particular forms and functions." Walter Crane, "Design in Two Parts", Magazine of Art 1893: 79-80, 131; 1898, 91.

11 Lewis F. Day kirjoittaa: "being accustomed to strict conditions saves the designer from the effect of customs in his own notion. Painting may be purely sensuous but decoration must be intelligent, too. Day demands that art should be judged by its own merits. Day, "The Lowly Arts": 343, 344.

12 Stefan Muthesius, "'We Do Not Understand What is Meant by "Company" Designing': Design versus Commerce in Late Nineteenth-Century English Furnishing", Journal of Design History 5-6, 1992:,

113, 115, 86.

13 Charles R. Eastlake, Hints on Household Taste.

Fourth Edition (London: Longmans, Green, and Co., 1868), 85.

14 G.T. Robinson, "The Year's Advance in Art Manufactures", The Art Journal 1883: 354.

15 "... why a work of Art, because it owes something to the machinery, should be false in taste or

unsatisfactory in ef-fect. In a certain sense all Art is, and must be, machine made. And he would have this certainty, that, if his design were only fit, the machine would do its work with unnerring accuracy Mr. Morris's theory, Art for the people by the people is a splendid dream. Perhaps it is more nearly to be realised by the aid of machinery than by any attempt to suppress it. The labour-saving machine saves the labourer's muscle as well as the outlay of the capitalist." Lewis F. Day, "Machine-made Art", The Art Journal 1885: 107-109.

$16 " . .$. to relieve (artist) altogether from the mechanical, commercial, and other cares common to craftsmanship is to cut off all communication with the base of his scarcely tenable professional position."

Lewis F. Day, "The Profession of Art", The Magazine of Art 1886: 122-123.

17 Walter Crane kirjoittaa kirjassaan The Claims of Decorative Art: "[--] artistic adaptation lags behind the scientific invention....commercial pressure and hurry is heavier upon (a designer)" Walter Crane, The Claims of Decorative Art (London: Lawrence and Bullen), 1892, 19; The Art Journalin pääkirjoituksessaan Lewis F. Day käsittelee muotoilijan kyvyttömyyttä tuottaa yksilöllisiä taideteoksia, koska koristetaiteen tuotannossa vaikuttavat monien tahojen edut. Lewis F. Day, "The Criticism of Decorative Art; an Editorial Statement". The Art Journal 1893: 64

18 Arthur Silver keskustelee aiheesta The Studion haastattelussa vuonna 1894: "The best manufacturers can teach the designer much more than he can teach them." [Anon.], "A Studio of Design. An Interview with Mr. Arthur Silver", The Studio 1894: 117, 119-121.

19 Frederick Wedmore, "A Designer of Paper Hangings. An Iterview with Mr. Walter Crane", The Studio, Volume Four, 1894: 79.

20 Reginald Blomfield, "Furniture", The Magazine of Art 1896: 490, 492.

21 Lewis F. Day, "William Morris and His Art", The Studio Easter Art Annual 1899: 10,14.

MA Juha Ågren toimii hallintotehtåvisså University of East Angliassa Norwichissa ja on aiemmin työskennellyt myo̊s useissa suomalaisissa museoissa. Artikkeli perustuu University of East Angliassa hyväksyttyyn MA by Research opinnåytetyőhön Commercial Genius: Marketing of Applied Arts Reform in Great Britain and Finland in the Last Quarter of the 19th Century. 